Case Report

\title{
Anomalous Right Coronary Artery from Left Main Coronary Artery and Subsequent Coursing between Aorta and Pulmonary Trunk
}

\author{
Deephak Swaminath, Ragesh Panikkath, Jason Strefling, Alvaro Rosales, \\ Roshni Narayanan, and Jason Wischmeyer
}

Department of Internal Medicine, TX Tech Health Sciences Center, Lubbock, TX 79430, USA

Correspondence should be addressed to Deephak Swaminath; deephak.swaminath@ttuhsc.edu

Received 6 July 2013; Accepted 18 November 2013

Academic Editor: Frank A. Pigula

Copyright (C) 2013 Deephak Swaminath et al. This is an open access article distributed under the Creative Commons Attribution License, which permits unrestricted use, distribution, and reproduction in any medium, provided the original work is properly cited.

Anomalous origin of left main coronary artery or right coronary artery from the aorta with subsequent coursing between the aorta and pulmonary trunk is rare and can be sometimes life threatening. After hypertrophic cardiomyopathy, coronary artery anomalies are the second most common cause of sudden cardiac deaths among young athletes. This is a case presentation of an anomalous origin of right coronary artery from left main coronary artery coursing between the pulmonary trunk and aorta. Patient presented with STEMI and had coronary bypass surgery.

\section{Case Description}

The patient is a 33-year-old male with an unremarkable past medical history and was transferred from an outside facility with an acute inferior myocardial infarction and ventricular tachycardia. Patient initially presented to the outside facility with complaints of chest pain. ECG showed lateral ST elevation and subtle inferior ST elevation. At the outside facility, patient developed ventricular tachycardia, and CPR was initiated with cardioversion 4 times before return of spontaneous circulation. The patient was subsequently intubated and transferred to our facility for further management.

Upon transfer, the patient was taken for left heart catheterization (LHC) and selective coronary angiography. Left heart catheterization and angiography showed an 80\% long tubular stenosis of the proximal to mid left anterior descending coronary artery (LAD) as well as an anomalous takeoff of the right coronary artery (RCA) from a left main coronary artery (Figures 2(a), 2(b), and 2(c)). LHC revealed markedly elevated left ventricular end diastolic pressure (LVEDP). The patient was aggressively diuresed after LHC revealed an elevated LVEDP. Dynamic ST changes improved with dual antiplatelet therapy, heparin, nitrates, and aggressive diuresis. Cardiac CT angiography with 3D reconstruction (Figures 1(a) and 1(b)) showed an anomalous origin of the right coronary artery coursing from the left main coronary artery between the aorta and pulmonary trunk. There was more than $70 \%$ narrowing at the origin of the right coronary artery from an apparent impingement from a plethoric pulmonary trunk. Cardiovascular surgery was consulted for surgical intervention. Aortocoronary bypass was performed with a left internal mammary artery bypass to the left anterior descending coronary artery and saphenous vein graft bypass to the right coronary artery. Postoperatively, the patient recovered and was discharged home.

\section{Discussion}

Coronary artery anomalies are found in $0.9 \%-1.3 \%$ of patients undergoing coronary angiography $[1,2]$. Anomalous origin of the left main coronary artery or right coronary artery from the aorta coursing between the aorta and pulmonary trunk is rare and can be sometimes life-threatening. 


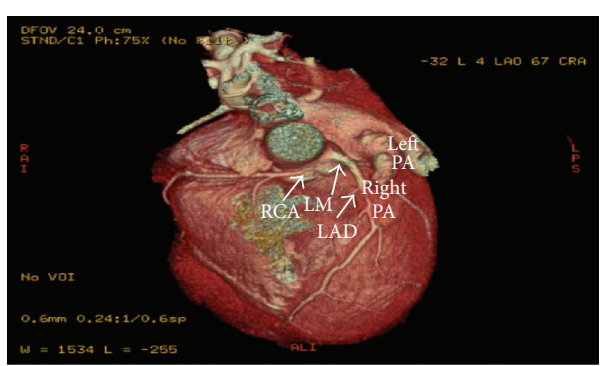

(a)

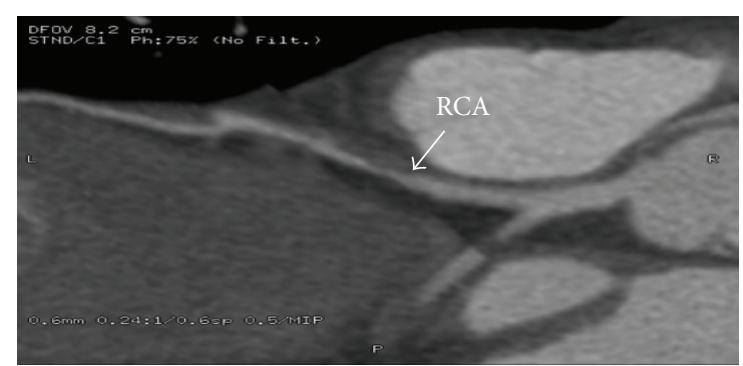

(b)

FIGURE 1: (a) Cardiac CT angiography with 3D reconstruction with digital subtraction of pulmonary arteries. (b) Cardiac CT angiography.

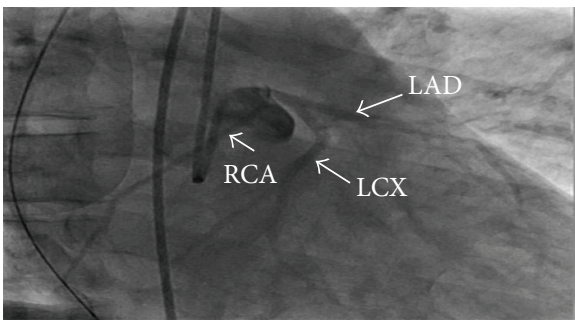

(a)

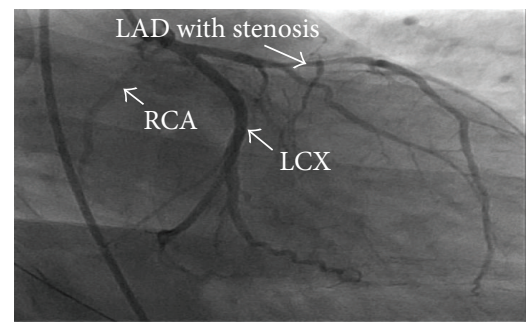

(b)

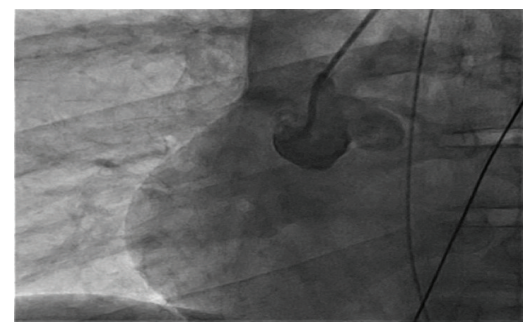

(c)

Figure 2: (a) Anomalous right coronary artery AP caudal projection with nonselective left coronary ostia angiogram. (b) Anomalous right coronary takeoff from left coronary artery in a RAO caudal projection of nonselective left coronary ostia angiogram. (c) Aortogram utilizing the JR4 catheter showing no separate right coronary ostium.

After hypertrophic cardiomyopathy, coronary artery anomalies are the second most common cause of sudden cardiac deaths among young athletes. Coronary artery anomalies are also the most common cause of nontraumatic sudden deaths in young American military recruits [2-4]. In a recent study, coronary artery anomalies were the cause of death in up to $19 \%$ of young athletes who died during or shortly after strenuous physical activity [3]. An interarterial course is clinically significant and carries a high risk for sudden cardiac death in young adults [5].

This is a case presentation of an RCA originating from the common left main coronary artery and coursing between the pulmonary trunk and aorta. The patient presented with ST segment elevation and life-threatening arrhythmia. Reduction of the right coronary blood flow secondary to impingement from a plethoric pulmonary trunk is likely attributed to the acute presentation. Notably, the patient did have anterolateral ST changes, suggestive of a hemodynamically significant LAD lesion, which may have contributed to the elevated LVEDP on presentation. In other presentations of compromising coronary anomalies, reduction in the coronary blood flow could be due to compression of the first segment of the coronary artery during its interarterial course, acute takeoffs, or slit-like orifices of these arteries. Anomalous coronary origin with interarterial coursing causes compromise in the coronary blood flow, which is evident during increases in pressure in the great vessels during exercise. Ischemic compromise of anomalous coronary arteries manifests as angina, syncope, congestive heart failure, arrhythmias, and sudden death [6-10].
However, coronary anomalies are often asymptomatic and might be discovered as an incidental finding. The physical exam, ECG, and stress test are generally unremarkable. An anomalous origin of a coronary artery and its route may be diagnosed by coronary angiography or more definitively by multislice computed tomography. Intravascular ultrasound provides high-resolution images to precisely evaluate coronary anomalies and luminal irregularity. The role of intravascular ultrasound was recently demonstrated in a small study that diagnosed an extrinsic compression of an anomalous coronary artery originating from the opposite sinus of Valsalva [11].

A study of two large registries composed of 27 young competitive athletes who died of sudden cardiac death (SCD) revealed that 23 had left main coronary artery from the right aortic sinus and 4 had a right coronary artery from the left sinus [12]. Estimates on rates of SCD with this condition come almost exclusively from autopsy data. Multiple studies focused on identifying specific factors that correlate with a higher likelihood of SCD in patient with coronary anomalies revealed that angle of take off, intramural course, slit-like ostium, interarterial course, vessel spasm, and intussusception of the anomalous vessel are the contributing factors [13]. However, in an attempt to identify specific features that were thought to contribute to risk of death, Taylor et al. looked at 30 pathology cases of anomalous coronary arteries and concluded that there were no anatomic features that could aid in risk assessment [14]. This assertion produces a quandary in risk assessment and likely means that these cases should be assessed individually on a case by case basis. 
Anomalous origin of the right coronary artery from the left coronary sinus is 6 times more common than the contrary situation of the left coronary artery originating from the right coronary sinus. However, fortunately this presentation is believed to be more benign than its counterpart which is more malignant. Consequently, although surgical repair is advisable for all patients with the left coronary artery originating from the right coronary sinus, this is not the case with the right coronary artery originating from the left coronary sinus, where it might it be advisable to only a selected subgroup of patients [15]. The surgical options for anomalous coronary origins from contralateral sinus include bypass grafting, reimplantation of the anomalous vessel into its appropriate sinus, patch augmentation with or without pulmonary artery translocation, and unroofing the anomalous vessel [16]. Nonsurgical strategies include the use of beta blockers and avoidance of participation in all competitive sports for patients [15].

\section{Conflict of Interests}

The authors declare that they have no conflict of interests.

\section{References}

[1] A. Yildiz, B. Okcun, T. Peker, C. Arslan, A. Olcay, and M. Bulent Vatan, "Prevalence of coronary artery anomalies in 12,457 adult patients who underwent coronary angiography," Clinical Cardiology, vol. 33, no. 12, pp. E60-E64, 2010.

[2] C. Erol and M. Seker, "Coronary artery anomalies: the prevalence of origination, course, and termination anomalies of coronary arteries detected by 64-detector computed tomography coronary angiography," Journal of Computer Assisted Tomography, vol. 35, no. 5, pp. 618-624, 2011.

[3] B. J. Maron, P. D. Thompson, J. C. Puffer et al., "Cardiovascular preparticipation screening of competitive athletes: a statement for health professionals from the Sudden Death Committee (Clinical cardiology) and Congenital Cardiac Defects Committee (Cardiovascular disease in the young), American Heart Association," Circulation, vol. 94, no. 4, pp. 850-856, 1996.

[4] R. E. Eckart, S. L. Scoville, C. L. Campbell et al., "Sudden death in young adults: a 25 -year review of autopsies in military recruits," Annals of Internal Medicine, vol. 141, no. 11, pp. 829-834, 2004.

[5] B. Sundaram, R. Kreml, and S. Patel, "Imaging of coronary artery anomalies," Radiologic Clinics of North America, vol. 48, no. 4, pp. 711-727, 2010.

[6] B. Brandt III, J. B. Martins, and M. L. Marcus, "Anomalous origin of the right coronary artery from the left sinus of Valsalva," The New England Journal of Medicine, vol. 309, no. 10, pp. 596-598, 1983.

[7] C. Frescura, C. Basso, G. Thiene et al., "Anomalous origin of coronary arteries and risk of sudden death: a study based on an autopsy population of congenital heart disease," Human Pathology, vol. 29, no. 7, pp. 689-695, 1998.

[8] J. M. Isner, E. M. Shen, E. T. Martin, and R. V. Fortin, "Sudden unexpected death as a result of anomalous origin of the right coronary artery from the left sinus of Valsalva," American Journal of Medicine, vol. 76, no. 1, pp. 155-158, 1984.
[9] D. Kimbiris, A. S. Iskandrian, B. L. Segal, and C. E. Bemis, "Anomalous aortic origin of coronary arteries," Circulation, vol. 58, no. 4, pp. 606-615, 1978.

[10] R. M. Reul, D. A. Cooley, G. L. Hallman, and G. J. Reul, “Surgical treatment of coronary artery anomalies: report of a 371/2-year experience at the Texas Heart Institute," Texas Heart Institute Journal, vol. 29, no. 4, pp. 299-307, 2002.

[11] D. M. de Oliveira, V. Gomes, and P. Caramori, "Intravascular ultrasound and pharmacological stress test to evaluate the anomalous origin of the right coronary artery," Journal of Invasive Cardiology, vol. 24, no. 6, pp. E131-E134, 2012.

[12] C. Basso, B. J. Maron, D. Corrado, and G. Thiene, "Clinical profile of congenital coronary artery anomalies with origin from the wrong aortic sinus leading to sudden death in young competitive athletes," Journal of the American College of Cardiology, vol. 35, no. 6, pp. 1493-1501, 2000.

[13] P. Angelini, J. A. Velasco, D. Ott, and G. R. Khoshnevis, "Anomalous coronary artery arising from the opposite sinus: descriptive features and pathophysiologic mechanisms, as documented by intravascular ultrasonography," Journal of Invasive Cardiology, vol. 15, no. 9, pp. 507-514, 2003.

[14] A. J. Taylor, J. P. Byers, M. D. Cheitlin, and R. Virmani, "Anomalous right or left coronary artery from the contralateral coronary sinus: "High-risk" abnormalities in the initial coronary artery course and heterogeneous clinical outcomes," American Heart Journal, vol. 133, no. 4, pp. 428-435, 1997.

[15] C. A. Warnes, R. G. Williams, T. M. Bashore et al., "ACC/AHA 2008 guidelines for the management of adults with congenital heart disease: a report of the American College of Cardiology/American Heart Association Task Force on Practice Guidelines (Writing Committee to Develop Guidelines on the Management of Adults With Congenital Heart Disease). Developed in Collaboration with the American Society of Echocardiography, Heart Rhythm Society, International Society for Adult Congenital Heart Disease, Society for Cardiovascular Angiography and Interventions, and Society of Thoracic Surgeons," American College of Cardiolog, vol. 52, no. 23, pp. el43e263, 2008.

[16] J. M. Penalver, R. S. Mosca, D. Weitz, and C. K. Phoon, "Anomalous aortic origin of coronary arteries from the opposite sinus: a critical appraisal of risk," BMC Cardiovascular Disorders, vol. 12, article 83, 2012. 


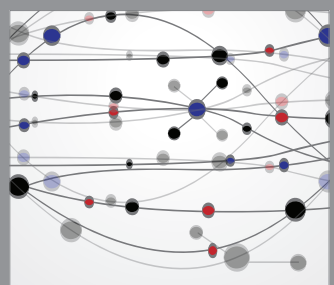

The Scientific World Journal
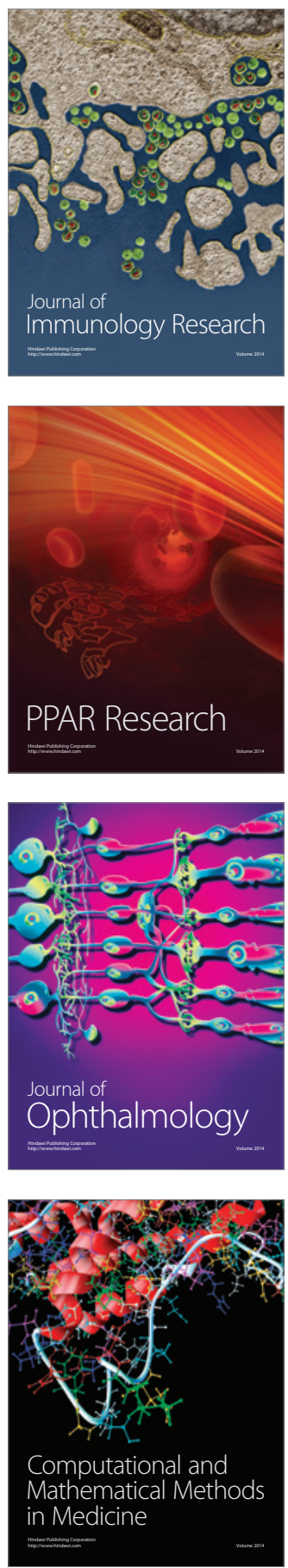

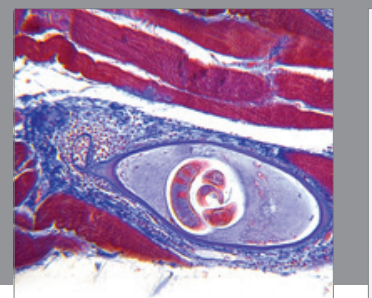

Gastroenterology

Research and Practice
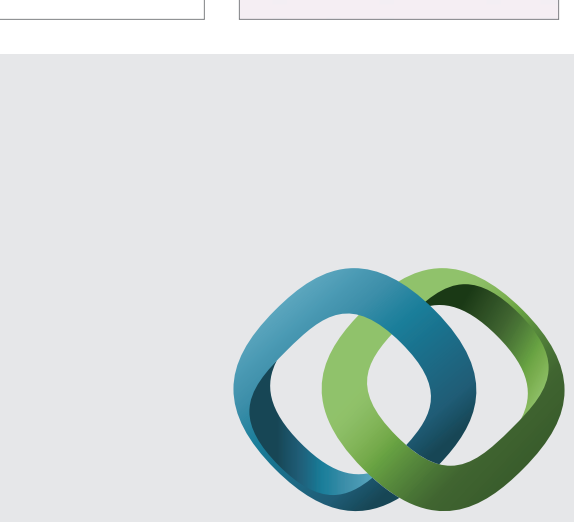

\section{Hindawi}

Submit your manuscripts at

http://www.hindawi.com
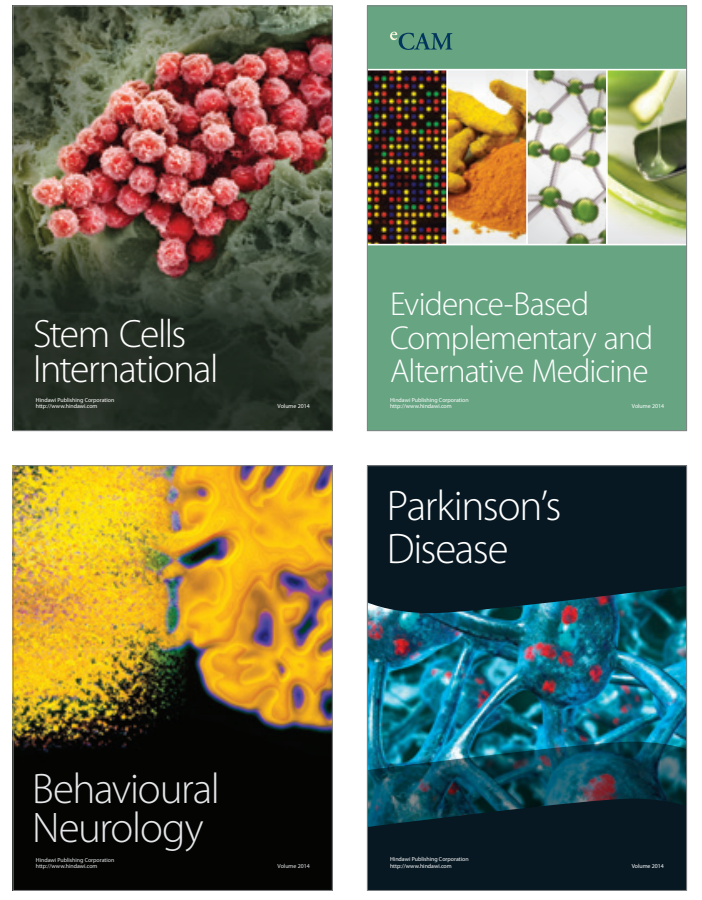
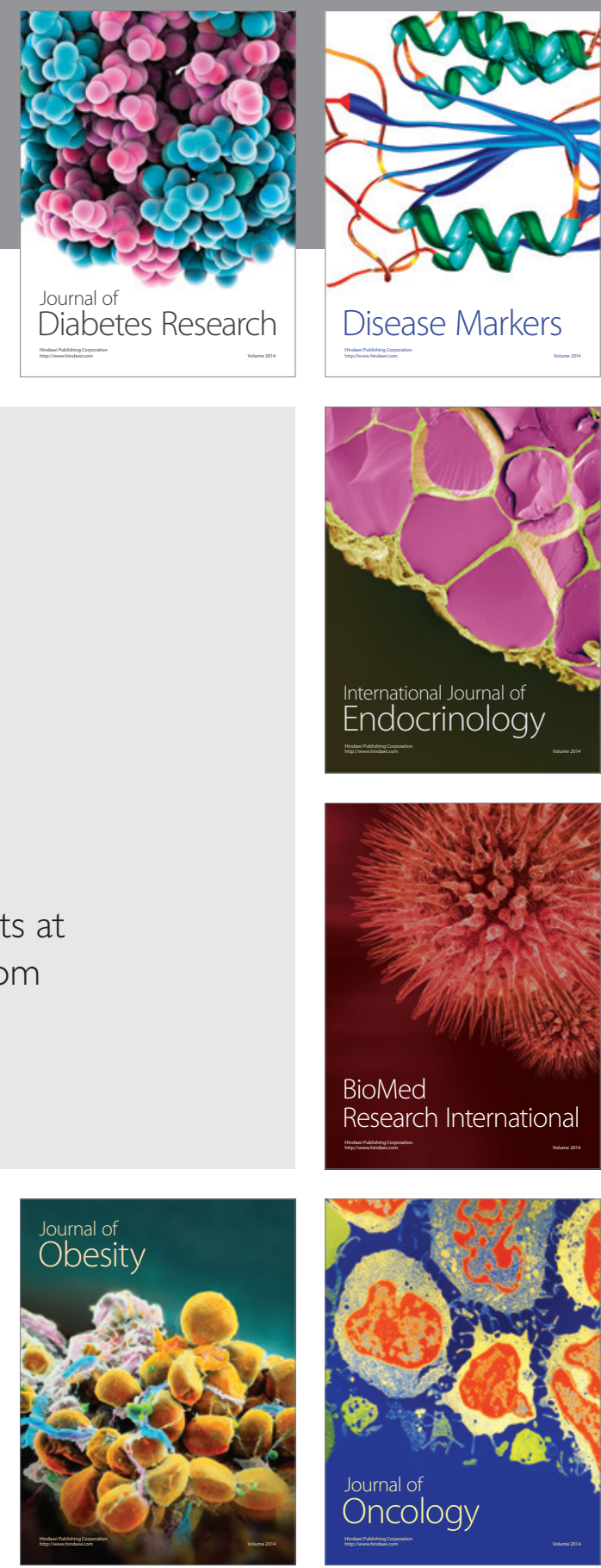

Disease Markers
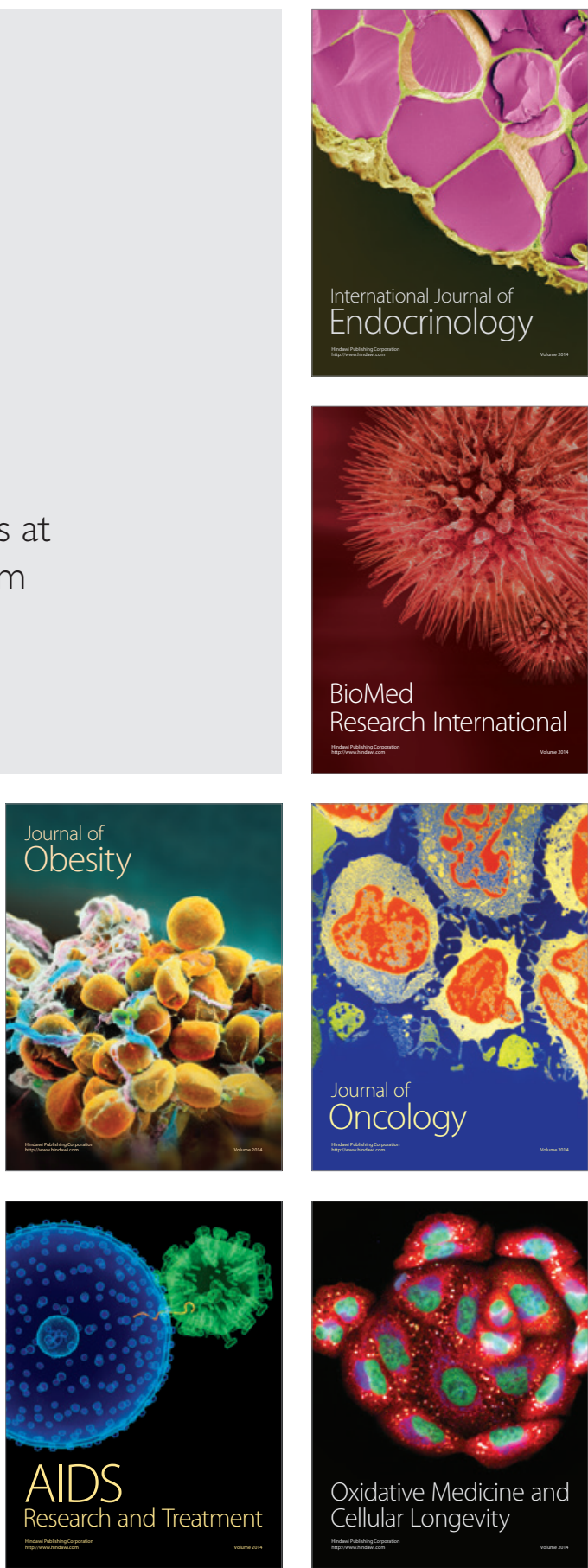